\title{
Dermatology Resident Education for Skin of Color
}

\author{
Nadine Shabeeb, MD, MPH
}

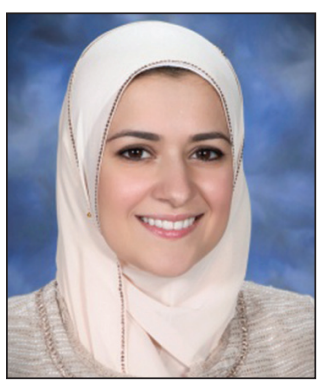

\section{RESIDENT PEARLS}

- Images of skin of color (SOC) are greatly underrepresented in dermatology educational resources.

- Inadequate training in recognizing skin disease in patients with darker skin can lead to delayed or missed diagnoses.

- There are various educational resources and opportunities available to improve and diversify dermatology education, ensuring the best possible care for patients with SOC.

Skin diseases often present differently in patients with darker skin, and certain features such as erythema may be more difficult to recognize. Dermatology residents learn various skin disease presentations through pattern recognition seen in the clinical setting, in patient photographs, and through other educational resources. Because images of skin of color (SOC) are underrepresented in many dermatology educational resources, residents should seek additional resources to enhance their knowledge and better serve their patients.

Cutis. 2020;106:E18-E20.

A $\mathrm{n}$ article recently was published in The New York Times with a headline that read, "Dermatology Has a Problem With Skin Color."1 The article featured interviews with many well-known dermatologists who are experts in skin of color (SOC), and their points followed a similar pattern-skin disease often looks different in patients with darker skin, and diagnoses often are delayed or missed altogether as a consequence of clinical uncertainty. The article included an interview with Jenna Lester, MD, who leads the SOC clinic at the University of California, San Francisco. In the article, she discussed how dermatologists are trained to recognize findings through pattern recognition. However, if we are only trained to diagnose dermatologic diseases on white skin, we will be unable to recognize diseases in patients with darker skin, leading to suboptimal patient care. ${ }^{1}$

Dermatology is a visual specialty, and residents go through thousands of photographs during residency training to distinguish different presentations and unique findings of a variety of skin diseases. Nevertheless, to Dr. Lester's point, our learning is limited by the photographs and patients that we see.

Additionally, residents training in locations without diverse patient populations rely even more on images in educational resources to recognize clinical presentations in patients with darker skin. A study was published in Cutis earlier this year that surveyed dermatology residents about multiethnic training in residency. ${ }^{2}$ It showed that residents training in less ethnically diverse areas such as the Midwest and Northwest were more likely to agree that dedicated multiethnic clinics and rotations are important to gain competence compared to residents training in more ethnically diverse regions such as the Southeast, Northeast, and Southwest. Most residents believed 1 to 5 hours per month of lectures covering conditions affecting SOC and/or multiethnic skin are needed to become competent. ${ }^{2}$ 


\section{Limitations of Educational Resources}

The images in dermatology educational resources do not reflect the diversity of our country's population. A research letter recently was published in the Journal of the American Academy of Dermatology (JAAD) in which the authors assessed the number of images of dark skin-Fitzpatrick skin types V and VI-in dermatology educational resources. ${ }^{3}$ The authors analyzed images from 8 resources commonly used to study dermatology, including 6 printed texts and 2 online resources. Of the printed texts, Andrews' Diseases of the Skin had the highest percentage of images of dark skin at 19.9\%. Overall, VisualDx had the highest percentage of photographs of dark skin at $28.5 \%$, while DermNet NZ had the lowest of all resources at only $2.8 \% .^{3}$

Similarly, a research letter published in the British Journal of Dermatology reviewed images in 2 standard dermatology textbooks. ${ }^{4}$ Although images of SOC made up $22 \%$ to $32 \%$ of the overall content, the number of images of sexually transmitted infections in SOC was disproportionate $(47 \%-58 \%)$ compared to images of non-sexually transmitted infections (28\%). The authors also stated that communities of color often have legacies of mistrust with the health care system, and diagnostic uncertainty can further impair the physician-patient relationship. ${ }^{4}$

The lack of diversity in clinical images and research was further exemplified by recent publications regarding the perniolike eruption associated with coronavirus disease 2019 (COVID-19), commonly referred to as COVID toes. A research letter was published in the British Journal of Dermatology earlier this year about the lack of images of SOC in publications about the cutaneous manifestations of COVID-19. ${ }^{5}$ At that time, there were zero published images of cutaneous COVID-19 manifestations in Fitzpatrick skin types V and VI, yet COVID-19 disproportionately affects Black individuals and other people of color. ${ }^{5,6}$ A case series recently was published in JAAD Case Reports that included images of cutaneous COVID-19 findings in patients with Fitzpatrick skin types III through V. ${ }^{7}$ The authors noted that the findings were more subtle on darker skin as the erythema was harder to discern. The inability to identify the perniolike eruption ultimately can delay diagnosis. ${ }^{7}$

\section{Resident Education}

Over the past few months, I have reflected on my role as a dermatology resident and my dedication to antiracism in my personal and professional life. It is not a valid response or excuse to say that certain diagnoses are harder to make because of darker skin tone. It is our responsibility to do better for all patients. To that end, our educational resources should reflect our entire patient population.

I have been working with my coresident Annika Weinhammer, MD, on a quality improvement project to strengthen our educational curriculum at the University of Wisconsin regarding SOC. This project aims to enhance our skills as dermatologists in diagnosing and treating diseases in SOC. Moving forward, we have set an expectation that all didactic lectures must include images of SOC. Below, I have listed some of our initiatives along with recommendations for educational resources. There are multiple dermatology textbooks focused on SOC, including the following:

- Clinical Cases in Skin of Color: Adnexal, Inflammation, Infections, and Pigmentary Disorders ${ }^{8}$

- Clinical Cases in Skin of Color: Medical, Oncological and Hair Disorders, and Cosmetic Dermatology ${ }^{9}$

- Dermatology Atlas for Skin of Color ${ }^{10}$

- Fundamentals of Ethnic Hair: The Dermatologist's Perspective $e^{11}$

- Light-Based Therapies for Skin of Color ${ }^{12}$

- Pediatric Skin of Color ${ }^{13}$

- Skin of Color: A Practical Guide to Dermatologic Diagnosis and Treatment ${ }^{14}$

- Taylor and Kelly's Dermatology for Skin of Color ${ }^{15}$

- Treatments for Skin of Color ${ }^{16}$

Our program has provided residents with Taylor and Kelly's Dermatology for Skin of Color ${ }^{15}$ and Treatments for Skin of Color. ${ }^{16}$ Residents and medical students should search their institution's electronic library for e-books and other resources including VisualDx, which includes many photographs of SOC that can be used and cited in resident didactics.

There also are a variety of online resources. Mind the Gap is a handbook written by Malone Mukwende, a medical student in London. ${ }^{17,18}$ The handbook focuses on common clinical signs and how they present in black and brown skin. Another online resource with clinical images is Skin Deep (https://dftbskindeep.com/), a project aimed at improving the diversity of pediatric skin images. An additional online resource is Brown Skin Matters on Instagram (@brownskinmatters) that shows photographs of dermatologic conditions in SOC; however, these photographs are submitted by users and not independently verified.

I also encourage residents to join the Skin of Color Society, which promotes awareness and excellence within the special interest area of SOC. Some of the society's initiatives include educational series, networking events, diversity town halls, and a scientific symposium. Patient information for common dermatologic diagnoses exists on the society's website (https://skinofcolorsociety.org/). The society waives membership fees for resident applicants who provide a letter of good standing from their residency program. The society hosted the Skin of Color Update virtually this year (September 12-13, 2020). It costs $\$ 49$ to attend, and the recorded lectures are available to stream through the end of 2020. Our department sponsored residents to attend virtually.

Finally, our department has been taking steps to implement antiracism measures in how we work, learn, conduct research, and treat patients. We are leading a resident book club discussing How to Be an Antiracist ${ }^{19}$ by Ibram X. Kendi. 
Residents are involved in the local chapter of White Coats for Black Lives (https://whitecoats4blacklives.org/). We also have compiled a list of antiracism resources that was shared with the department, including books, documentaries, podcasts, local and online Black-owned businesses to support, and local Black-led nonprofits.

\section{Final Thoughts}

Dermatology residents must be comfortable diagnosing and treating diseases in darker skin tones to provide the best possible care for patients with SOC. Although some common dermatology educational resources have a paucity of clinical images of SOC, there are a variety of additional educational resources through textbooks and websites.

\section{REFERENCES}

1. Rabin RC. Dermatology has a problem with skin color. New York Times. August 30, 2020. https://www.nytimes.com/2020/08/30/health /skin-diseases-black-hispanic.html. Accessed October 5, 2020.

2. Cline A, Winter R, Kouroush S, et al. Multiethnic training in residency: a survey of dermatology residents. Cutis. 2020;105:310-313.

3. Alvarado SM, Feng H. Representation of dark skin images of common dermatologic conditions in educational resources: a crosssectional analysis [published online June 18, 2020]. J Am Acad Dermatol. doi:10.1016/j.jaad.2020.06.041.

4. Lester JC, Taylor SC, Chren MM. Under-representation of skin of colour in dermatology images: not just an educational issue. $\mathrm{Br} J$ Dermatol. 2019;180:1521-1522

5. Lester JC, Jia JL, Zhang L, et al. Absence of images of skin of colour in publications of COVID-19 skin manifestations. $\mathrm{Br} J$ Dermatol. 2020;183:593-595.
6. Golden SH. Coronavirus in African Americans and other people of color. Johns Hopkins Medicine website. https://www.hopkinsmedicine.org/health/conditions-and-diseases/coronavirus/covid19-racialdisparities. Published April 20, 2020. Accessed October 5, 2020.

7. Daneshjou R, Rana J, Dickman M, et al. Pernio-like eruption associated with COVID-19 in skin of color. JAAD Case Rep. 2020;6:892-897.

8. Love PB, Kundu RV, eds. Clinical Cases in Skin of Color: Adnexal, Inflammation, Infections, and Pigmentary Disorders. Switzerland: Springer; 2016.

9. Love PB, Kundu RV, eds. Clinical Cases in Skin of Color: Medical, Oncological and Hair Disorders, and Cosmetic Dermatology. Switzerland: Springer; 2016.

10. Jackson-Richards D, Pandya AG, eds. Dermatology Atlas for Skin of Color. New York, NY: Springer; 2014.

11. Aguh C, Okoye GA, eds. Fundamentals of Ethnic Hair: The Dermatologist's Perspective. Switzerland: Springer; 2017.

12. Baron E, ed. Light-Based Therapies for Skin of Color. London: Springer; 2009.

13. Silverberg NB, Durán-McKinster C, TayY-K, eds. Pediatric Skin of Color. New York, NY: Springer; 2015.

14. Alexis AF, Barbosa VH, eds. Skin of Color: A Practical Guide to Dermatologic Diagnosis and Treatment. New York, NY: Springer; 2013.

15. Taylor SC, Kelly AP, Lim H, et al. Taylor and Kelly's Dermatology for Skin of Color. 2nd ed. New York, NY: McGraw Hill Professional; 2016.

16. Taylor SC, Badreshia-Bansal S, CalendarVD, et al. Treatments for Skin of Color. China: Saunders Elsevier; 2011.

17. Page S. A medical student couldn't find how symptoms look on darker skin. he decided to publish a book about it. Washington Post. July 22, 2020. https://www.washingtonpost.com/lifestyle/2020/07/22 /malone-mukwende-medical-handbook/. Accessed October 5, 2020.

18. Mukwende M, Tamony P, Turner M. Mind the Gap: A Handbook of Clinical Signs in Black and Brown Skin. London, England: St. George's University of London; 2020. https://www.blackandbrownskin.co.uk /mindthegap. Accessed October 5, 2020.

19. Kendi IX. How to Be an Antiracist. New York, NY: Random House; 2019. 